\title{
SHORT COMMUNICATION \\ EXPANSION OF LACTATION SUPPORT SERVICES TO NEONATAL INTENSIVE CARE UNIT
}

\author{
Iva Holmquist ${ }^{1,2}$, Vanda Boštíkováa ${ }^{2,3}$, Hana Střítecká, ${ }^{4,}$, Hana Zmrzlá, Radek Pohnán ${ }^{6}$, Anna Mydlilová7 \\ ${ }^{1}$ Emory University Hospital Midtown, Maternity Centre, Atlanta, Georgia, USA \\ 2Department of Epidemiology, Faculty of Health Sciences, University of Defence, Hradec Králové, Czech Republic \\ ${ }^{3}$ Faculty of Science, University of Hradec Králové, Hradec Králové, Czech Republic \\ ${ }^{4}$ Department of Military Internal Medicine and Military Hygiene, Faculty of Health Sciences, University of Defence, Hradec Králové, Czech \\ Republic \\ ${ }^{5}$ Department of Paediatrics, Hospital Svitavy, Svitavy, Czech Republic \\ ${ }^{6}$ Military University Hospital Prague, Prague, Czech Republic \\ ${ }^{7}$ National Centre for Breastfeeding, Thomayer Hospital, Prague, Czech Republic \\ ${ }^{8}$ Faculty of Health Sciences, Department of Specialised Subjects and Practical Skills, Palacký University Olomouc, Olomouc, Czech Republic
}

Key words: public health, neonatal intensive care unit, infant, breastfeeding, lactation support, perinatal centres, United States, Czech Republic

Address for correspondence: V. Boštíková, Department of Epidemiology, Faculty of Health Sciences, University of Defence, Třebešská 1575, 50001 Hradec Králové, Czech Republic. E-mail: vanda.bostikova@unob.cz

https://doi.org/10.21101/cejph.a5200

\section{INTRODUCTION}

While the current hospital-based lactation support practices in the United States may not be applicable to hospital practices in the European Union, there are some surprising similarities. More specifically, it is the increasing motion towards short maternity leave within the population of professional women in the Czech Republic. In the United States the common maternity leave ranges between six weeks for vaginal deliveries and 12 weeks for caesarean sections. Furthermore, in the United States many neonatal intensive care units (NICU) wards are unable to provide housing for mothers during their infant's hospitalization. This commentary addresses concerns, practices and lactation care recommendation with specific focus on women that are unable to remain in hospitals while their infants are in NICU.

Every year 4 million babies are delivered in the United States and nearly $15 \%$ are delivered prematurely (1). Many of these infants have to be admitted to NICU as they have an abnormal transition predisposing them to life threatening complications (2). Premature infants born with very low birth weight represent 54\% of all infants' deaths in the United States of America (3). Muraskas and Parsi (1) found that $25 \%$ of NICU population consists of full-term infants that are admitted for multiple medical diagnoses requiring intensive treatment.

All infants admitted to NICU whether premature or sick obtain essential protection from serious illness and health complications if they receive their mother's breastmilk (4). One of the most serious and potentially fatal complications that premature infant can face is necrotizing enterocolitis (NEC). According to Parker et al. (5) 3-10\% of very low birth weight infants are diagnosed with NEC. Ganapathy et al. (6) found that when premature infants were diagnosed with medical NEC they were on average hospitalized 11.7 days longer and encountered additional $\$ 74,004.00$ in medical cost. Infants with surgical NEC were hospitalized for additional 43.1 days and their care incurred additional cost of $\$ 198,040$. Ganapathy et al. (6) further concluded that $100 \%$ breastmilk diet in preterm infants decrease the incidence of NEC by $63 \%$. Breastmilk and especially mother's own breastmilk provides the infant with irreplaceable nutritional and non-nutritional benefits and enhances health status of the infant not only during hospitalizations but also during the entire lifespan.

Mothers with infants in NICU are challenged with a number of barriers to maintain adequate lactation, initiate early breastfeeding and successful transition to exclusive breastfeeding. Consistent professional help from a Board Certified Lactation Consultant (IBCLC) can prevent these challenges. Presence of dedicated IBCLC and NICU increases the numbers of infants receiving breastmilk (7).

\section{Practice Description}

Initially, most hospitals provide appropriate care to breastfeeding and breast-milk feeding mothers with premature and sick infants that have been admitted to NICU. Labour and delivery or postpartum nursing staff educates the mother within 3-6 hours after delivery how to hand express colostrum and initiate the use of hospital grade breast pump. IBCLC provides a detailed education that is based on the patient's specific needs and develops an individual plan on how to maintain lactation while taking into consideration patient's emotional needs. This plan includes education on use of hospital grade pump, information on how to establish and maintain milk production, initiation of breast- 
feeding, and storage/transport of breast-milk. While the patient remains on postpartum unit, the IBCLC commonly offers daily comprehensive follow-up consultations to reinforce the provided information and to address mother's individual needs.

When the mother is discharged home she can request individual consultation but the continuation of consistent lactation care is often limited and may fall onto the NICU nurses. Although the NICU staff may understand the importance of breastfeeding and breastmilk feeding, their main focus is to care for infant's immediate medical needs. In addition, the NICU nurses may not have the skills set to provide holistic breastfeeding support the mother may need in order to maintain lactation. As result of the limited access, IBCLCs may be called only as a last resort when the mother's milk supply has dramatically decreased and the NICU is faced with increased cost of donor's breast milk. Other reason for lactation consultant maybe that an infant is ready for discharge and the IBCLC is asked to assist with transition to exclusive breastfeeding. Unfortunately, due to the common lack of IBCLC staffing many hospitals are unable to offer evidence-based lactation support and to provide mothers with comprehensive individualized care even after they are discharged from hospital.

\section{Lactation Support Recommendation}

The most important role of the NICU designated lactation consultant is to assist mothers with breastfeeding, pumping challenges and to ensure maximum milk production. It can be estimated that one full time lactation consultant can provide up to 1,960 consultation hours annually. The suggested lactation consultations after the mother is discharged home should include:

- first follow up visit no later than seven days after delivery (90 minutes consultation): to evaluate milk production and observe pumping technique; adjust pumping schedule to mother's activities of daily life; review milk storage and transport, availability of appropriate hospital grade breast pump; assist with kangaroo care and hand-expression of breast milk into infant's mouth and/or early breastfeeding (if infant is unstable, 30 minutes would be postponed to later visits);

- second follow up visit 14 days postpartum (30 minutes): to evaluate milk production, discuss infant's progress, assist with early breastfeeding and start planning discharge;

- third follow up visit 21 days postpartum (30 minutes): to evaluate milk production, discuss infant's progress, assist with breastfeeding, continue with discharge plan;

- fourth follow up visit 2-3 days prior discharge (60 minutes): to assess breastfeeding, assist with transition to exclusive breastfeeding with specific focus on signs and indication of adequate feedings, finalize discharge plans and discuss outpatient follow up care.

The proposed lactation care schedule designates 3.5 hours of direct care and 0.5 hours of indirect care per patient totaling 4.0 hours. In comparison, Mannel and Mannel (8) found in their retrospective study that the ideal consultation time for mother with an infant in NICU should consist of 5.5 hours of direct care during the infant's hospital stay. In a survey of FTE allocation in 15 hospitals across the U.S., Francis-Clegg and Francis (9) determined that some hospitals were staffing NICU's with 1.0 FTE of designated lactation support per every 235 of annually admitted breastfeeding infants. The generally recognized staffing guidelines are based on the Association of Women's Health and Obstetric and Neonatal Nurses (10) recommendation that suggests availability of 1.9 FTEs of lactation support for every 1,000 deliveries in a tertiary hospital. However, these staffing guidelines do not designate how the FTEs are allocated to individual areas of Women's Health centres.

While the most important objective is to assist breastfeeding and pumping moms within NICU it is also important to consider how evidence-based breastfeeding practices and policies will positively affect health of this vulnerable population long term. Research has shown that when evaluating breastmilk fed premature infants born with very low birth weight between the ages of 18-30 months they perform much better in motor development, cognitive development and behaviour than formula fed infants (11). Furthermore, the use of human milk and early initiation of breastfeeding in premature infants is significantly associated with long-term cardiovascular benefits, decreased obesity, gastrointestinal benefits, improved immunology, and psychological benefits (11).

\section{Hospital Based Breastfeeding Support in the Czech Republic}

Breastfeeding support in the Czech Republic is based on the United Nations Convention on the Rights of the Child that clearly designated breastfeeding as fundamental component of child's right (12). Unfortunately, the governmental support and protection of breastfeeding is inadequate. Major issues include lack of implementation of the International Code of Marketing of Breastmilk Substitutes at national level, poor compliance with standards of the Baby Friendly Hospital Initiative and inconsistent systematic data on use of complementary feedings (13). As result exclusive breastfeeding rates in the Czech Republic are declining.

According to the International Board of Lactation Consultant Examiners (IBCLCE), currently there are 12 perinatal centres in the Czech Republic. Thanks to the efforts of the National Centre for Breastfeeding training healthcare professionals on promotion and support of breastfeeding, patients of most of maternity centres, including the perinatal centres caring for premature infants, have access to lactation counsellors. The National Centre for Breastfeeding also educates peer counsellors and therefore improves availability of breastfeeding support in community settings. However, the National Centre for Breastfeeding is not adequately funded, supported or even recognized by the Czech government.

While breastfeeding rates in the USA may still not be comparable to the breastfeeding rates in the Czech Republic, they are consistently improving as the legislative support and public awareness is improving. Governmental support of breastfeeding was particularly triggered in 2011 by the Surgeon General's Call to Action to Support Breastfeeding. Hospital practices significantly improved when in 2014 the Joint Commission included breastfeeding exclusivity in the Perinatal Care Measures. Number of "baby-friendly" hospitals considerably increased between 2011-2015 as a result of the National Institute for Children's Health Quality (NICHQ) initiative Best Fed Beginnings. Current legislative IBCLC licensure changes, which continue to occur at state level, will improve local protection and accessibility to community breastfeeding support. 


\section{CONCLUSION}

In the U.S., the Healthy People 2020 defined breastfeeding as a national priority and acknowledged importance of the overall cost of sub-optimal breastfeeding $(14,15)$. It is estimated that if $90 \%$ of families with newborns would comply with the Healthy People 2020 breastfeeding recommendations the U.S. would save $\$ 13$ billion annually in health expenses and would prevent 911 of infant deaths (16). Similar proportionally appropriate conclusions could be drawn for the population in the Czech Republic, even though it may be difficult to persuade the local government to improve its approach to support breastfeeding and recognize the long-term financial and health potential of improved breastfeeding rates. While financial investments in improvement of breastfeeding practices may seem significant, given the extensive benefits and preventable cost associated with sub-optimal breastfeeding especially in the vulnerable population of premature infants, these investments are more than justifiable just as they are ethical.

\section{Conflict of Interests}

None declared

\section{REFERENCES}

1. Muraskas J, Parsi K. The Cost of saving the tiniest lives: NICUs versus prevention. Virtual Mentor. 2008 Oct 1;10(10):655-8.

2. Allison BA, Burcin E. Triage, not just for the emergency department: a discussion of the appropriate level of care for the transitioning infant. Neonatal Netw. 2011 Mar-Apr;30(2):99-103.

3. Johnson TJ, Patel AL, Bigger HR, Engstrom JL, Meier PP. Economic benefits and costs of human milk feedings: a strategy to reduce the risk of prematurity-related morbidities in very-low-birth-weight infants. Adv Nutr. 2014 Mar 1;5(2):207-12.

4. Bernaix LW, Schmidt CA, Arrizola M, Iovinelli D, Medina-Poelinez C. Success of a lactation education program on NICU nurses' knowledge and attitudes. J Obstet Gynecol Neonatal Nurs. 2008 Jul-Aug;37(4):436-45.

5. Parker LA, Krueger C, Sullivan S, Kelechi T, Mueller M. Effect of breast milk on hospital costs and length of stay among very low-birth-weight infants in the NICU. Adv Neonatal Care. 2012 Aug;12(4):254-9.
6. Ganapathy V, Hay JW, Kim JH. Costs of necrotizing enterocolitis and cost-effectiveness of exclusively human milk-based products in feeding extremely premature infants. Breastfeed Med. 2012 Feb;7(1):29-37.

7. Dweck N, Augustine M, Pandya D, Valdes-Greene R, Visintainer P, Brumberg HL. NICU lactation consultant increases percentage of outborn versus inborn babies receiving human milk. J Perinatol. 2008 Feb;28(2):136-40.

8. Mannel R, Mannel RS. Staffing for hospital lactation programs: recommendations from a tertiary care teaching hospital. J Hum Lact. 2006 Nov;22(4):409-17.

9. Francis-Clegg S, Francis DT. Improving the "bottom line": financial justification for the hospital-based lactation consultant role. Clin Lact. 2011;2(1):19-25.

10. Association of Women's Health, Obstetric \& Neonatal Nursing. Guidelines for professional registered nurse staffing for perinatal units executive summary. Nurs Womens Health. 2011 Feb-Mar;15(1):81-4.

11. Cross J. Neuroprotective core measure 7: optimizing nutrition - breastfeeding, human milk and attachment. Newborn Infant Nurs Rev. 2015;15(3):128-31.

12. United Nations Human Rights, Office of the High Commissioner. Convention on the Rights of the Child [Internet]. Geneva: OHCHR [cited 2018 Aug 3]. Available from: https://www.ohchr.org/en/professionalinterest/ pages/crc.aspx.

13. International Baby Food Action Network. Report on the situation of infant and young child feeding in Czech Republic [Internet]. IBFAN; 2014 [cited 2018 Aug 3]. Available from: https://webcache.googleusercontent.com/ search?q=cache:K8h8Wi9j4aEJ:https://tbinternet.ohchr.org/Treaties/CESCR/Shared\%2520Documents/CZE/INT CESCR CSS CZE 16929 E. docx $+\& \mathrm{~cd}=4 \& \mathrm{hl}=$ en $\& \mathrm{ct}=\mathrm{clnk} \& \mathrm{gl}=\mathrm{us}$.

14. U.S. Department of Health and Human Services. Executive summary: The Surgeon General's Call to Action to Support Breastfeeding [Internet]. Washington: U.S. Department of Health and Human Services, Office of the Surgeon General; 2011 [cited 2018 Aug 3]. Available from: https:// www.surgeongeneral.gov/library/calls/breastfeeding/executivesummary. pdf.

15. U.S. Department of Health \& Human Services, Office of Disease Prevention and Health Promotion. Maternal, infant, and child health [Internet]. Rockville: ODPHP; 2015 [cited 2018 Aug 3]. Available from: https:// www.healthypeople.gov/2020/topics-objectives/topic/maternal-infantand-child-health.

16. Bartick M, Reinhold A. The burden of suboptimal breastfeeding in the United States: a pediatric cost analysis. Pediatrics. 2010 May;125(5):e1048-56.

Received September 17, 2017 Accepted in revised form August 3, 2018

\section{The 80th Birthday of Professor Drahoslava Hrubá, CSc.}

In 2018, Professor Drahoslava Hrubá, CSc., member of the Editorial Board of the Central European Journal of Public Health, celebrated her 80th birthday.

The Editorial Board thanks Professor Hrubá for her hard work and support of the journal, and wishes her success and happiness in the coming years. 